\title{
Phosphorylated STAT3 expression linked to SOCS3 methylation is associated with proliferative ability of gastric mucosa in patients with early gastric cancer
}

\author{
HIROKAZU FUKUI ${ }^{1}$, JIRO WATARI ${ }^{1}$, XINXING ZHANG ${ }^{1}$, YING RAN $^{1}$, TOSHIHIKO TOMITA ${ }^{1}$, \\ TADAYUKI OSHIMA ${ }^{1}$, SEIICHI HIROTA ${ }^{2}$ and HIROTO MIWA ${ }^{1}$ \\ ${ }^{1}$ Division of Gastroenterology, Department of Internal Medicine; ${ }^{2}$ Department of Surgical Pathology, \\ Hyogo College of Medicine Hospital, Nishinomiya, Hyogo 663-8501, Japan
}

Received May 27, 2019; Accepted February 7, 2020

DOI: 10.3892/ol.2020.11462

\begin{abstract}
Gastric cancers (GCs) may develop in the gastric mucosa after elimination of Helicobacter pylori (H. pylori) using eradication therapy. Cytokine signaling is a key mechanism underlying GC development and progression, and STAT3 signaling may serve a central role in gastritis-associated tumorigenesis. In the present study, suppressor of cytokine signaling 3 (SOCS3) methylation was examined, as an activator of phosphorylated (p-)STAT3 expression in the non-neoplastic gastric mucosa (non-NGM) of patients with early GC. The methylation status of the SOCS3 gene promoter was analyzed using methylation-specific PCR in the non-NGM of patients with or without early GC. Expression levels of p-STAT3 and Ki67 were investigated immunohistochemically in non-NGM with early GC before and after $H$. pylori eradication. In non-NGM, SOCS3 promoter methylation was detected in $17 / 51$ patients (33.3\%) with early GC. In those patients, the non-NGM labeling indices of both Ki67 and p-STAT3 were significantly higher compared with that in patients with early GC without SOCS3 methylation. A significant correlation between Ki67 and p-STAT3 expression levels was demonstrated in the non-NGM of patients with early GC. In patients with early GC without SOCS3 methylation, the labeling indices of both Ki67 and p-STAT3 in non-NGM were significantly reduced after $H$. pylori eradication, whereas
\end{abstract}

Correspondence to: Dr Hirokazu Fukui, Division of Gastroenterology, Department of Internal Medicine, Hyogo College of Medicine Hospital, 1-1 Mukogawa, Nishinomiya, Hyogo 663-8501, Japan

E-mail: hfukui@hyo-med.ac.jp

Abbreviations: STAT3, signal transducer and activator of transcription 3; SOCS3, suppressor of cytokine signaling 3; non-NGM, non-neoplastic gastric mucosa; GC, gastric cancer

Key words: SOCS3, methylation, STAT3, gastric cancer, proliferation, eradication no such change was observed in patients with early GC with SOCS3 methylation. SOCS3 methylation is associated with continuous p-STAT3 overexpression and enhanced epithelial cell proliferation in non-NGM of patients with early GC.

\section{Introduction}

It has been demonstrated that inflammation serves important roles in the development, growth and/or invasion of various types of cancer (1-3). For example, Helicobacter pylori (H.pylori) infection causes chronic inflammation in the gastric mucosa and is subsequently involved in the development of gastric cancers (GCs) (4,5), although the precise mechanism remains unclear. Proinflammatory cytokines function not only in the gastrointestinal immune system, but also in cell growth and/or apoptosis in the gastric mucosa, resulting in the development and progression of GCs $(6,7)$. Downstream of cytokine signaling, various activated transcription factors, such as signal transducer and activator of transcriptions (STATs), NF- $\kappa$ B and AP-1, serve a role in the regulation of target genes that are involved in gastric carcinogenesis (7). Among these cytokine-associated transcription factors, STAT3 has been highlighted in inflammation-associated carcinogenesis in various organs, such as lung, pancreas and liver (8-12). Notably, mice possessing STAT3 hyperactivation, which lack the negative feedback by SHP2/SOCS3 binding onto gp130, develop gastric tumors accompanied by chronic gastritis $(13,14)$; however, the clinical significance of overactivated STAT3 and its function in human gastric carcinogenesis remains to be clarified. STAT3 is constitutively activated in numerous types of cancer, for example lung and pancreatic cancer and hepatocellular carcinoma (15-17), and serves a role in cell proliferation, migration and in anti-apoptosis by activating target genes, including cyclin D1, matrix metalloproteases or $B c l-x L(18,19)$. It has also been shown that Ki67 is a well-known marker to evaluate the ability of cell proliferation (20). Hence, the present study aimed to investigate the correlation between phosphorylated (p-)STAT3 and Ki67 expression levels in patients with early GC.

$H$. pylori infection over two decades causes a sequence of histological changes in the non-neoplastic gastric mucosa 
(non-NGM), referred to as Correa's hypothesis $(4,5)$, along with simultaneous accumulation of genetic and epigenetic alterations, for example microsatellite instability or p53 and E-cadherin mutations $(21,22)$. Cytokine signaling activates cytokine receptor-associated Janus kinase (JAK) $(23,24)$, which in turn phosphorylates STAT3, rendering it functional $(23,24)$. On the other hand, the suppressor of cytokine signaling 3 (SOCS3) can bind to cytokine receptors and JAK to inhibit JAK/STAT3 signaling, acting as a tumor suppressor in a negative feedback loop $(25,26)$. In this regard, alteration of SOCS3 appears to be a crucial step of carcinogenesis in various organs, including the head and neck, pancreas, liver, blood and brain (27-31). The present study investigated SOCS3 methylation and p-STAT3 expression levels in the non-NGM of patients with early GC in relation to non-NGM cell proliferative ability that may impact GC development.

\section{Materials and methods}

Patients and biopsies. A total of fifty-one patients with early GC (39 male and 12 female; median age 72; age range 48-87) and 22 patients with gastritis without GC (12 males and 10 females; median age 64; age range 30-81) were enrolled into the present study between January 2011 and March 2013 at the Hyogo College of Medicine Hospital (Hyogo, Japan). Patients with early GC were diagnosed by previous endoscopic examination with biopsy at the Hyogo College of Medicine Hospital. The exclusion criteria were as follows: i) Patients with malignancy in other organs; ii) patients with an allergy to drugs used for $H$. pylori eradication; iii) patients regularly taking a nonsteroidal anti-inflammatory drug, including aspirin; iv) patients with a history of esophagectomy or gastrectomy; and v) patients who were determined by their physicians to be unqualified for any other reason, for example severe pneumonia. Biopsy specimens were routinely obtained from the non-NGM of all patients at the greater curvature of the mid corpus of the stomach (at least $3 \mathrm{~cm}$ far from the lesion), where biopsy was possible before and after treatment with endoscopic submucosal resection (ESD). All patients with early GC underwent ESD and were followed up using endoscopic examination 1 year later. Among them, 13 patients received $H$. pylori eradication after ESD treatment and biopsy specimens were obtained for a second time from the same location at the greater curvature of the stomach when undergoing follow-up endoscopic examinations 1 year after ESD. The severity of gastric atrophy was classified by endoscopic examination according to the criteria of Kimura and Takemoto, as reported previously $(32,33)$. The serum was isolated from blood samples from the patients before ESD treatment. The serum $H$. pylori immunoglobulin $\mathrm{G}(\mathrm{IgG})$ antibody titer was analyzed using an ELISA kit (E plate test; Eiken Chemical Co., Ltd.). Written informed consent was provided by all the patients and the present study was approved by The Ethics Committee of Hyogo College of Medicine.

DNA extraction and bisulfite treatment. DNA was isolated from biopsy specimens using a QIAamp DNA Micro kit (Qiagen $\mathrm{GmbH}$ ). The DNA (500 ng) was modified with sodium bisulfite using an EpiTect Bisulfite kit (Qiagen $\mathrm{GmbH}$ ), as recommended in the manufacturer's protocol (34).
Sodium bisulfite converts unmethylated cytosine to uracil, whereas methylated cytosines are resistant (35). DNA samples were subsequently purified using the Wizard DNA Clean-Up System (Promega Biotechnologies, Inc.) and precipitated in $16 \mu 1$ water, as previously reported (34).

Qualitative methylation-specific PCR (MSP) for SOCS3 gene. Bisulfite-treated genomic DNA was amplified using either methylated or unmethylated specific primer sets, using the sequences as follows: Methylated specific forward, 5'-TATATA TTCGCGAGCGCGGTTT-3', and reverse, 5'-CGCTGCGCC CAGATGTT-3'; unmethylated specific forward, 5'-TGTGGT GGTTGTTTATATATTTGTGAGTGTGGTT-3', and reverse, 5'-CAACCAACAATAACCCACACTACACCCA-3' (36). The amplifications were performed in a total reaction volume of $50 \mu \mathrm{l}$ containing $20 \mathrm{pmol}$ of each set of primers, $1.25 \mathrm{U}$ EpiTaq HS DNA polymerase, PCR buffer with $\mathrm{MgCl}_{2}$ (both Takara Bio, Inc) and $0.3 \mathrm{mM}$ each dNTP. The PCR was conducted as follows: Initial denaturation at $95^{\circ} \mathrm{C}$ for $5 \mathrm{~min} ; 30$ cycles at $98^{\circ} \mathrm{C}$ for $10 \mathrm{sec} ; 64^{\circ} \mathrm{C}$ for $30 \mathrm{sec} ; 72^{\circ} \mathrm{C}$ for $30 \mathrm{sec}$; final extension at $72^{\circ} \mathrm{C}$ for $7 \mathrm{~min}$. The PCR products were electrophoresed using $2 \%$ agarose gel and then visualized using ethidium bromide staining under UV illumination.

Immunohistochemistry. The biopsy specimens were fixed in $10 \%$ formalin solution at room temperature overnight and embedded in paraffin. Immunohistochemical staining for Ki67 and p-STAT3 was performed using an Envision kit (Dako; Agilent Technologies) as previously described $(37,38)$, using the primary antibodies anti-Ki67 antibody (1:50; cat no. IR626; Dako; Agilent Technologies) and anti-phospho-specific STAT3 (Tyr705) antibody (1:15; cat no. 9131; Cell Signaling Technology). In brief, $4-\mu$ m-thick sections were placed on slides, deparaffinized in xylene and rehydrated through a descending series of ethanol $(100,90,80$ and $70 \%)$. The slides were then placed in Dako REAL Target Retrieval Solution (Dako; Agilent Technologies) and treated by microwave heating (MI-77; Azumaya) at $400 \mathrm{~W}$ and $95^{\circ} \mathrm{C}$ for $10 \mathrm{~min}$ to facilitate antigen retrieval, followed by pretreatment with $0.3 \%$ $\mathrm{H}_{2} \mathrm{O}_{2}$ in methanol for $20 \mathrm{~min}$ at room temperature to quench endogenous peroxidase activity. The sections were then washed 3 times by phosphate-buffered saline and followed by the treated with blocking buffer (Protein Block Serum-Free; Dako Agilent Technologies) for $30 \mathrm{~min}$ at room temperature. Thereafter, the sections were incubated with the primary antibodies for $60 \mathrm{~min}$ at room temperature, washed 3 times in phosphate-buffered saline and incubated with anti-mouse (ready to use; cat. no. K4001) or anti-rabbit IgG antibody (ready to use; cat. no. K4003) (both Dako; Agilent Technologies, Inc.) for $30 \mathrm{~min}$ at room temperature and washed 3 times in phosphate-buffered saline. Finally, the sections were incubated in 3,3'-diaminobenzidine tetrahydrochloride with $0.05 \%$ hydrogen peroxide for $3 \mathrm{~min}$ at room temperature and then counterstained with Mayer's hematoxylin for $1 \mathrm{~min}$ at room temperature.

To evaluate the immunoreactivity of Ki67 and p-STAT3, 100 epithelial cells were counted in 5 different visual fields for each section under light microscope (magnification, $\mathrm{x} 400$ ). The labeling index was calculated as the percentage of positive cells. 


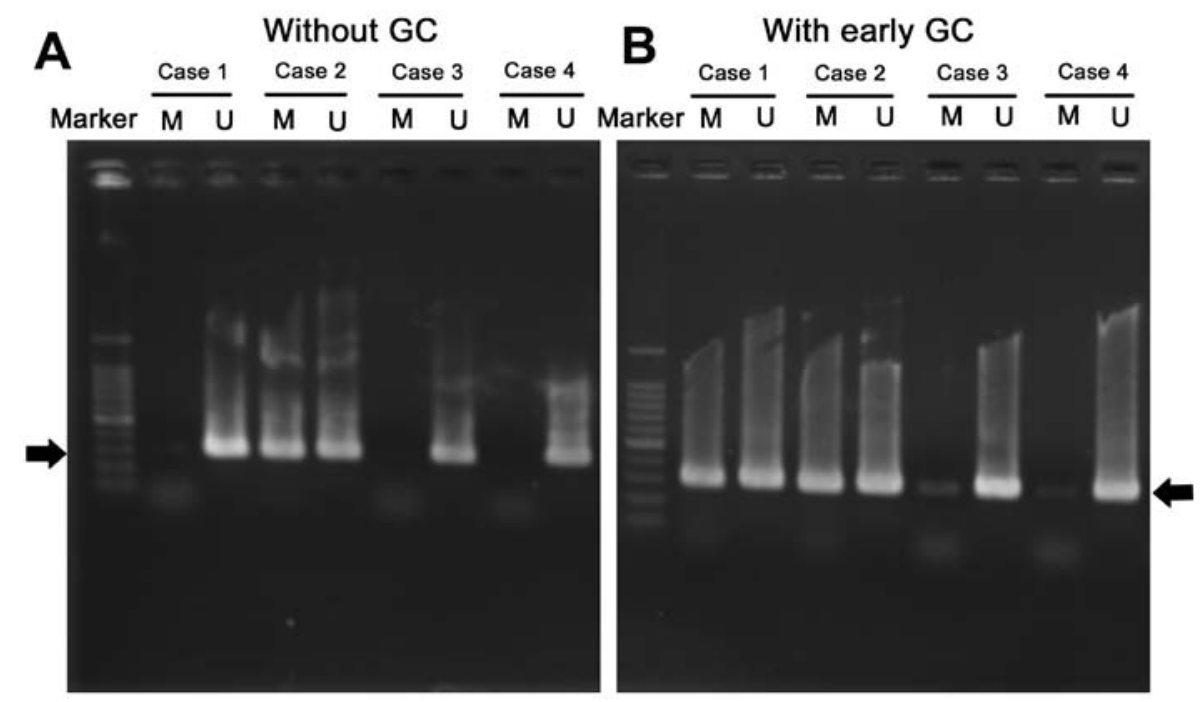

Figure 1. Methylation specific PCR analysis of the suppressor of cytokine signaling 3 promoter region in the non-neoplastic gastric mucosa of patients without (A) or with (B) early GC. Representative cases are presented. Black arrows indicating the position of PCR products expected. U, unmethylated; M, methylated; $\mathrm{GC}$, gastric cancer.

Statistical analysis. All values were expressed as the mean \pm standard error of the mean. The significance of differences between two unpaired groups was assessed using a Student's t-test or Mann-Whitney U-test. Clinicopathological parameters including sex, age, anti-H. pylori antibody, gastric atrophy and SOCS3 methylation positivity, were assessed using $\chi^{2}$ analyses. The correlation between p-STAT3 and Ki67 labeling index was assessed using linear regression analysis. For multiple comparisons, the paired data before and after eradication were analyzed using two-way repeated measures ANOVA followed by Bonferroni's correction. $\mathrm{P}<0.05$ was considered to indicate a statistically significant difference.

\section{Results}

Association between the characteristics of patients and SOCS3 methylation in the non-NGM of patients with or without early $G C$. Representative electrophoresis gels of MSP products for SOCS3 are shown in Fig. 1. The clinical and endoscopic features of the patients with or without early GC are presented in Table I. A total of 17 out of the 51 patients with early GC (33.3\%) had SOCS3 methylation. Sex, age, anti-H. pylori antibody and gastric atrophy were not significantly associated with SOCS3 methylation positivity in the non-NGM of patients with early GC. The positivity of SOCS3 methylation in the non-NGM was significantly higher in patients with early GC compared with those without $(\mathrm{P}=0.020)$ (Table I). Parameters including age $(\mathrm{P}=0.0003)$, anti-H. pylori antibody $(\mathrm{P}=0.0001)$ and gastric atrophy $(\mathrm{P}=0.0005)$ were significantly different between patients with early GC and those without (Table I). Regarding anti-H.pylori-IgG level, $19 / 51$ patients with early GC were negative; however, 14 (74\%) of these 19 patients showed an open-type gastric atrophy. Overall, 6/51 early GC patients was negative for anti- $H$. pylori antibody due to past eradication therapy. SOCS 3 methylation was detected in $3 / 6$ of these patients with early GC. SOCS3 methylation positivity was detected in 4/10 (40\%) patients with early GC with closed-type atrophy and in $13 / 41(32 \%)$ of patients with open-type atrophy.
A total of 22 patients had chronic gastritis but no cancerous lesions. Among them, 15 patients were positive for both anti-H. pylori antibody and gastric atrophy and $2(13.3 \%)$ were also positive for SOCS3 methylation. A total of 5 patients were negative for both anti- $H$. pylori antibody and gastric atrophy and had no SOCS3 methylation (Table II). The remaining two patients were negative for anti- $H$. pylori antibody after eradication but positive for gastric atrophy. These patients had no SOCS3 methylation. When the 15 patients with anti-H.pylori antibody-positivity were compared with 5 patients with anti- $H$. pylori antibody negativity, the presence of gastric atrophy was significantly associated with $H$. pylori infection $(\mathrm{P}<0.0001)$ (Table II).

The group of patients without early GC contained patients positive and negative for $H$. pylori infection. The 15 patients who were positive for both anti- $H$. pylori antibody were isolated, then gastric atrophy and the associations between characteristics of patients and SOCS3 methylation in the non-NGM of patients with or without early gastric cancer were re-analyzed. Subsequently, age, gastric atrophy and the positivity of SOCS3 methylation in the non-NGM was significantly higher in patients with early GC compared with that in patients without early $\mathrm{GC}(\mathrm{P}=0.047, \mathrm{P}=0.0002$ and $\mathrm{P}=0.046$, respectively; Table III).

Correlation between SOCS3 methylation and p-STAT3 and Ki67 expression levels in the non-NGM in patients with early $G C$. p-STAT3 immunoreactivity was observed in the nuclei of the non-neoplastic epithelial cells in the gastric mucosa (Fig. 2A). The p-STAT3 labeling index in the non-NGM was significantly higher in early GC patients with SOCS3 methylation compared with those without $(\mathrm{P}<0.001$; Fig. 2B). Ki67 immunoreactivity (as a cell proliferation marker) was also observed in the nuclei of the non-neoplastic epithelial cells in the gastric mucosa (Fig. 2C). The Ki67 labeling index in the non-NGM was significantly higher in patients with early GC with SOCS3 methylation compared with those without ( $\mathrm{P}<0.001$; Fig. 2D). 
Table I. Characteristics of patients with $(n=51)$ and without $(n=22)$ early gastric cancer.

\begin{tabular}{|c|c|c|c|c|c|}
\hline \multirow[b]{2}{*}{ Characteristic } & \multicolumn{2}{|c|}{ Without early GC } & \multicolumn{2}{|c|}{ With early GC } & \multirow[b]{2}{*}{$\begin{array}{l}\text { P-value, with } \\
\text { vs. without }\end{array}$} \\
\hline & $\begin{array}{l}\text { Without } \\
\text { early GC }\end{array}$ & $\begin{array}{l}\text { P-value in } \\
\text { 'Without } \\
\text { GC group' }\end{array}$ & With early GC & $\begin{array}{c}\text { P-value in } \\
\text { 'With } \\
\text { GC group' }\end{array}$ & \\
\hline $\operatorname{Sex}, \mathrm{n}(\mathrm{n} ; \%)^{\mathrm{a}}$ & & NS & & NS & NS \\
\hline Male & $12(0 ; 0.0)$ & & $39(12 ; 30.8)$ & & \\
\hline Female & $10(2 ; 20.0)$ & & $12(5 ; 41.7)$ & & \\
\hline Mean age \pm SEM (range), years & $61.1 \pm 2.9(30-81)$ & NS & $71.1 \pm 1.2(48-87)$ & NS & 0.0003 \\
\hline$<65$ years, $\mathrm{n}(\mathrm{n} ; \%)^{\mathrm{a}}$ & $11(0 ; 0.0)$ & & $13(4 ; 30.8)$ & & 0.041 \\
\hline$\geq 65$ years, $\mathrm{n}(\mathrm{n} ; \%)^{\mathrm{a}}$ & $11(2 ; 18.2)$ & & $38(13 ; 34.2)$ & & \\
\hline Anti-H. pylori antibody, $\mathrm{n}(\mathrm{n} ; \%)^{\mathrm{a}}$ & & NS & & NS & 0.0001 \\
\hline Negative & $5(0 ; 0.0)$ & & $19(6 ; 31.6)$ & & \\
\hline Positive & $15(2 ; 13.3)$ & & $26(8 ; 30.8)$ & & \\
\hline Era-negative & $2(0 ; 0.0)$ & & $6(3 ; 50.0)$ & & \\
\hline Gastric atrophy, $\mathrm{n}(\mathrm{n} ; \%)^{\mathrm{a}}$ & & NS & & NS & 0.0005 \\
\hline None & $5(0 ; 0.0)$ & & $0(0 ; 0.0)$ & & \\
\hline Closed & $7(1 ; 14.3)$ & & $10(4 ; 40.0)$ & & \\
\hline Open & $10(1 ; 10.0)$ & & $41(13 ; 31.7)$ & & \\
\hline SOCS3 methylation positive, $\mathrm{n}(\%)$ & & & & & 0.020 \\
\hline Positive & $2(9.1)$ & & $17(33.3)$ & & \\
\hline Negative & $20(90.9)$ & & $34(66.7)$ & & \\
\hline
\end{tabular}

${ }^{a}$ The number of patients positive for SOCS3 methylation and the percentage. GC, gastric cancer; NS, not significant; Era-negative, negative for Anti-H. pylori antibody post eradication therapy; SOCS3, suppressor of cytokine signaling $3 ; \mathrm{H}$. pylori, Helicobacter pylori; SEM, standard error of the mean.

Table II. Characteristics in patients without early gastric cancer, with or without $H$. pylori infection.

\begin{tabular}{lcc}
\hline Characteristic & H.pylori-negative $(\mathrm{n}=5)$ & H. pylori-positive $(\mathrm{n}=15)$ \\
\hline Sex, $(\mathrm{n} ; \%)^{\mathrm{a}}$ & $2(0 ; 0.0)$ & $10(0 ; 0.0)$ \\
Male & $3(0 ; 0.0)$ & $5(2 ; 40.0)$ \\
Female & $66.8 \pm 2.3(62-74)$ & $58.1 \pm 3.9(30-81)$ \\
Mean age \pm SEM (range), years & $2(0 ; 0.0 \%)$ & $8(0 ; 0.0)$ \\
$<65$ years, n $(\mathrm{n} ; \%)^{\mathrm{a}}$ & $3(0 ; 0 \%)$ & $7(2 ; 28.6)$ \\
$\geq 65$ years, $\mathrm{n}(\mathrm{n} ; \%)^{\mathrm{a}}$ & & $0(0 ; 0.0)$ \\
Gastric atrophy, years, $\mathrm{n}(\mathrm{n} ; \%)^{\mathrm{a}}$ & $5(0 ; 0.0)$ & $7(1 ; 14.3)$ \\
None & $0(0 ; 0.0)$ & $8(1 ; 12.5)$ \\
Closed & $0(0 ; 0.0)$ & $2(13.3)$ \\
Open & $0(0.0)$ & $\mathrm{NS}$ \\
SOCS3 methylation positive & & $<0.0001$ \\
\hline
\end{tabular}

${ }^{a}$ The number of patients positive for SOCS3 methylation and the percentage. GC, gastric cancer; NS, not significant; H.pylori, Helicobacter pylori; SOCS3, suppressor of cytokine signaling 3; SEM, standard error of the mean.

It is known that activated STAT3 plays a pivotal role in cell proliferation $(11,12)$. Therefore, the correlation between p-STAT3 and Ki67 expression levels was investigated in the non-NGM of patients with early GC. The labeling index of Ki67 was positively correlated with that of $\mathrm{p}-\mathrm{STAT} 3$ ( $\mathrm{r}=0.414 ; \mathrm{P}=0.0025$; Fig. 3).
Effect of $H$. pylori eradication on SOCS3 methylation and p-STAT3/Ki67 expression in the non-NGM in patients with early $G C$. A total of 13 patients were investigated who received $H$. pylori eradication therapy after ESD and in whom gastric biopsy sampling had been performed prior to 
Table III. Characteristics in patients with early gastric cancer with $H$. pylori infection and patients with early gastric cancer without $H$. pylori infection.

\begin{tabular}{lccc}
\hline Characteristics & $\begin{array}{c}\text { Without early GC } \\
\text { H.pylori-positive, } \mathrm{n}=15\end{array}$ & With early GC, $\mathrm{n}=51$ & $\begin{array}{c}\text { P-value, } \\
\text { with vs. without }\end{array}$ \\
\hline Sex, $\mathrm{n}(\mathrm{n} ; \%)^{\mathrm{a}}$ & $10(0 ; 0.0 \%)$ & & NS \\
Male & $5(2 ; 40.0 \%)$ & $39(12 ; 30.8)$ & \\
Female & $58.1 \pm 3.9(30-81)$ & $71.1 \pm 1.2(48-87)$ & 0.0002 \\
Mean age \pm SEM (range), years & $8(0 ; 0.0)$ & $13(4 ; 30.8)$ & $0.047^{\mathrm{b}}$ \\
$<65$ years, $\mathrm{n}(\mathrm{n} ; \%)^{\mathrm{a}}$ & $7(2 ; 28.6)$ & $38(13 ; 34.2)$ & $0.0002^{\mathrm{b}}$ \\
$\geq 65$ years, $\mathrm{n}(\mathrm{n} ; \%)^{\mathrm{a}}$ & & 0 & \\
Gastric atrophy, $(\mathrm{n} ; \%)^{\mathrm{a}}$ & $0(0 ; 0.0)$ & $10(4 ; 0.0)$ & \\
None & $7(1 ; 14.3)$ & $41(13 ; 31.7)$ & $0.046^{\mathrm{b}}$ \\
Closed & $8(1 ; 12.5)$ & $17(33.3)$ & \\
Open & $2(13.3)$ & & \\
SOCS3 methylation positive & & & \\
\hline
\end{tabular}

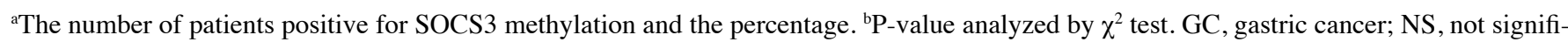
cant; H. pylori, Helicobacter pylori; SOCS3, suppressor of cytokine signaling 3; SEM, standard error of the mean.
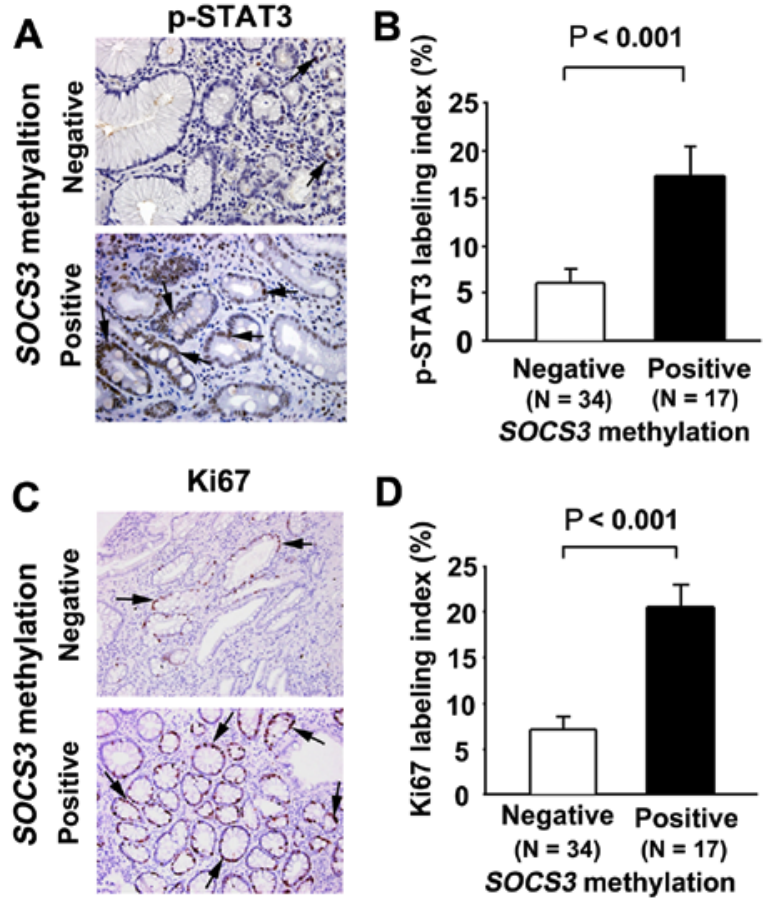

Figure 2. Immunostaining of p-STAT3 and Ki67 in the non-NGM of patients with early GC. (A) Immunohistochemical localization of p-STAT3 in the non-NGM of patients with early GC positive and negative for SOCS3 methylation. (B) Comparison of p-STAT3 labeling index between negative and positive groups for SOCS3 methylation. (C) Immunohistochemical localization of Ki67 in non-NGM of patients with early GC positive and negative for SOCS3 methylation. (D) Comparison of Ki67 labeling index between negative and positive groups for SOCS3 methylation. p-, phosphorylated; STAT3, signal transducer and activator of transcription 3; non-NGM, non-neoplastic gastric mucosa; GC, gastric cancer; SOCS3, suppressor of cytokine signaling 3.

and one year following eradication. A total of 4 patients were positive for SOCS3 methylation, whereas 9 were negative (Fig. 4); although the small number examined was a limitation in this study.

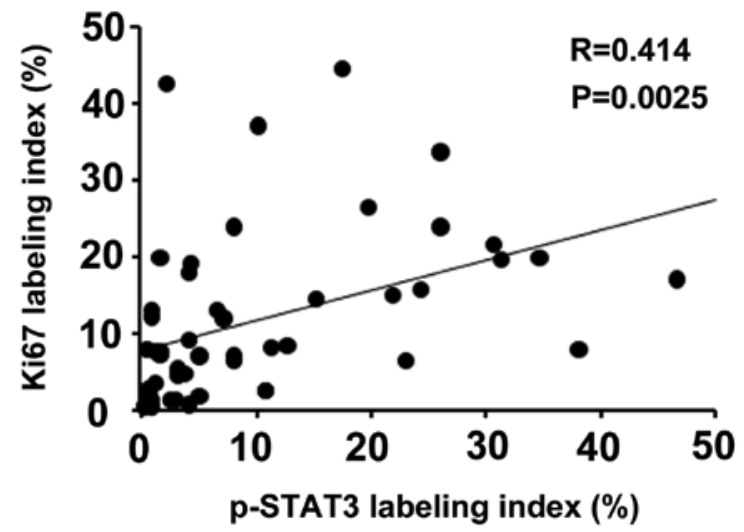

Figure 3. Correlation between p-STAT3 and Ki67 labeling indices in the non-neoplastic gastric epithelium of patients with early gastric cancer. p-, phosphorylated; STAT3, signal transducer and activator of transcription 3 .

Before $H$. pylori eradication, the p-STAT3 labeling index in the non-NGM was significantly higher in the SOCS3 methylation-positive group (33.6 \pm 4.9$)$ than in negative group $(17.7 \pm 3.6)(\mathrm{P}<0.05)$. After eradication, the $\mathrm{p}$-STAT3 labeling index was significantly reduced in the SOCS3 methylation-negative group $(9.6 \pm 2.1)(\mathrm{P}<0.05)$ but remained unchanged in the SOCS3 methylation-positive group. The p-STAT3 labeling index remained significantly higher in the SOCS3 methylation-positive group $(25.8 \pm 4.7)$ compared with that in the negative group (Fig. 4A).

Ki67 expression levels were also investigated in the aforementioned 13 patients. Before H. pylori eradication, the Ki67 labeling index in the non-NGM was significantly higher in the SOCS3 methylation-positive group (23.0 \pm 3.7$)$ compared with that in the negative group $(10.3 \pm 2.1)(\mathrm{P}<0.05)$. This difference was sustained even after eradication $(\mathrm{P}<0.05)$. In the SOCS3 methylation-negative group, the Ki67 labeling index was significantly reduced by eradication treatment $(4.5 \pm 1.2)$, 

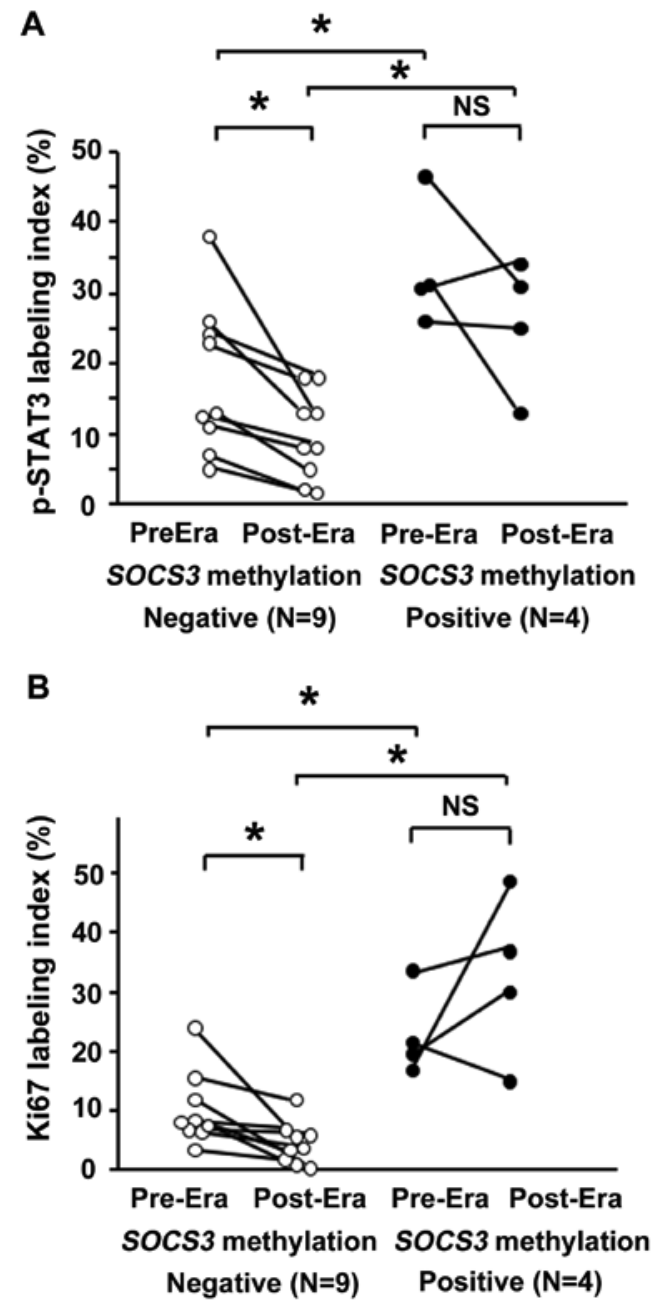

Figure 4. Effect of H.pylori eradication on (A) p-STAT3 and (B) Ki67 expression levels in the non-neoplastic gastric epithelium of patients with early GC, in relation to SOCS3 methylation status. Bars represent the average. ${ }^{*} \mathrm{P}<0.05$. NS, not significant; Era, eradication; p-, phosphorylated; STAT3, signal transducer and activator of transcription 3; SOCS3, suppressor of cytokine signaling $3 ;$ H. pylori, Helicobacter pylori; Era, eradication.

whereas it was not significantly changed after eradication in

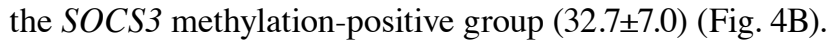

\section{Discussion}

SOCS3 methylation frequently occurs in various epithelial and non-epithelial malignancies, including head and neck squamous cell carcinoma, pancreatic cancer, hepatocellular carcinoma, multiple myeloma and glioma (27-31). SOCS3 methylation is also detectable in various inflammation-associated gastroenterological malignancies, including hepatocellular carcinoma (39), Barrett's adenocarcinoma (40) and ulcerative colitis-associated types of colorectal cancer (41), suggesting the involvement of SOCS3 methylation in different types of inflammatory gastric cancer. In the present study, the status of SOCS3 methylation in the non-NGM, where GC arises, was investigated, and it was revealed that $S O C S 3$ methylation was detectable in patients with early GC and in patients with non-GC gastritis It is still unclear whether SOCS3 methylation is specific for H. pylori-related gastritis however, it is worth noting that the patients with gastritis with positive SOCS3 methylation had also been infected with $H$. pylori. The occurrence of SOCS3 methylation in non-NGM of patients with early GC was significantly higher compared with that in patients without GC $(\mathrm{P}=0.020)$. However, as the group without GC included $H$. pylori positive- and negative-patients, $H$. pylori-positive patients without early GC and early GC patients were further compared. As a result, the occurrence of SOCS3 methylation in non-NGM was still higher in patients with early GC compared with patients without early GC (Table III), suggesting that SOCS3 methylation may occur in the development of $H$. pylori-induced gastritis-carcinoma. However, as a limitation of the present study, the number of patients with $H$. pylori-infected gastritis was small. Therefore, the aforementioned hypothesis requires further investigation. In addition, it is well-known that the frequency of methylation increases with age $(42,43)$ and the grade of atrophy and age was greater in patients with early GC compared with those without (Table I). Thus, the aging factor and its associated gastric atrophy may affect the frequency of SOCS3 methylation when comparing the patients with early GC and those without. However, when the patients with early GC where analyzed alone, the occurrence of SOCS3 methylation in non-NGM was not affected by age or gastric atrophy. This may suggest that SOCS3 methylation in the non-NGM may not always occur in older patients with high-grade gastric atrophy.

SOCS3 is a negative regulator of JAK/STAT signaling and may act as a tumor suppressor $(25,26)$. Thus, dysfunction of SOCS3 resulting from methylation could lead to continuous activation of STAT3 signaling and SOCS3 methylation has been reported to be associated with activation of STAT3 phosphorylation in some types of carcinogenesis, such as pancreatic cancer, ulcerative colitis-associated cancer and cholangiocarcinoma $(31,41,44)$. In the present study, the association between SOCS3 methylation status and p-STAT3 expression levels were investigated in non-neoplastic epithelial cells in the gastric mucosa of patients with early GC. It was revealed that p-STAT3 expression was higher in patients positive for SOCS3 methylation. Activated STAT3 serves a role in cell proliferation in carcinogenesis $(45,46)$ and therefore the association between SOCS3 methylation status and Ki67 expression levels were also investigated. The results from the present study revealed that $\mathrm{Ki} 67$ expression levels were enhanced in patients with early GC positive for SOCS3 methylation, consistent with a previous study which revealed that enhanced $\mathrm{Ki} 67$ expression was associated with the suppression of SOCS3 expression levels in hepatocellular carcinoma (47). Moreover, the expression levels of p-STAT3 and Ki67 showed a positive association in the non-NGM of patients with early GC in the present study, similar to a previous report in which p-STAT3 expression and Ki67 expression levels were associated in glioblastomas (48). The findings of the present study suggest that the activated STAT3 signaling associated with SOCS3 methylation may accelerate the proliferative ability of gastric epithelial cells in individuals at risk of developing GC lesions. It is of concern that the expression levels of p-STAT3 and Ki67 were compared irrespective of $H$. pylori status using a serum anti- $H$. pylor $i$ test, especially as anti-H. pylori-IgG expression levels are 
often negative in patients with severe atrophic stomach mucosa and/or widely spread intestinal metaplasia $(49,50)$. Indeed, in regardless of eradication, 19/51 patients with early GC were negative for anti- $H$. pylori-IgG level in the present study and $74 \%$ of such patients showed an open-type gastric atrophy. It was a limitation in the present study that $H$.pylori status was determined using anti-H. pylori-IgG expression levels. However, it is notable that SOCS3 methylation often occurs in patients with open- and closed-type gastric atrophy, suggesting that SOCS3 methylation may occur in an early phase of progression of gastric atrophy.

The effect of $H$. pylori eradication on p-STAT3 and Ki67 expression levels in the non-NGM of patients with early GC after ESD treatment were subsequently investigated. p-STAT3 expression levels were significantly reduced following eradication therapy in patients with early GC with negative SOCS3 methylation, whereas no such effect was evident in patients with early GC with positive SOCS3 methylation. Similarly, eradication therapy significantly reduced the expression levels of Ki67 in patients with early GC with negative SOCS3 methylation, but not significantly different in those with $S O C S 3$ methylation. It has been suggested that genetic abnormalities, such as microsatellite instability or methylations $(51,52)$, that accumulate in the gastric mucosa during $H$. pylori-induced chronic gastritis are difficult to reverse using eradication therapy (52) and that GCs often occur in patients after successful H. pylori eradication (53). In the present study, early GC developed in 6 patients after eradication and SOCS3 methylation was detected in 3 of these patients. It was also demonstrated that eradication had no effect on p-STAT3 and Ki67 expression levels in the non-NGM of patients with early GC with positive SOCS3 methylation. The aforementioned findings from the present study and previous research suggest that the non-NGM retains a high propensity for cell proliferation in patients with early GC with positive SOCS3 methylation. However, it is a limitation of the present study that the number of patients followed-up after eradication was small to divide the patients according to SOCS3 methylation status. Thus, to verify the results in the present study, large scale studies, with a large number of patients during follow-up after eradication, will be required.

In summary, it has been demonstrated that SOCS3 methylation frequently occurs in the non-NGM of patients with early GC. Moreover, it was shown that $H$. pylori eradication does not affect p-STAT3 or Ki67 expression levels in the non-NGM of patients with early GC with positive SOCS3 methylation. The results from the preset study suggest that SOCS3 methylation is associated with continuous p-STAT3 overexpression and enhancement of epithelial cell proliferation in the non-NGM of patients with early GC, serving a role in the development of GC. However, the present study had several limitations including the lack of quantitative evaluation of SOCS3 methylation and the suitability of sampling of biopsy specimen. For instance, if biopsy specimens had been collected near the cancerous lesions, the detection rate of SOCS3 methylation might be increased. In addition, quantitative evaluation of SOCS3 methylation might clarify more significant correlations among patients' characteristics, p-STAT3 and Ki67 expression levels in patients with early GC. Further studies are required to investigate whether SOCS3 methylation could be a predictive marker for the development of first and/or metachronous GC in a future large-scale studies.

\section{Acknowledgements}

The authors would like to thank Miss Chiyomi Ito and Miss Mayumi Yamada (Hyogo College of Medicine) for their technical assistance.

\section{Funding}

This study was supported in part by Grants-In-Aid for Scientific Research (grant no. 17K0936) from the Ministry of Education, Culture, Sports, Science and Technology, Japan.

\section{Availability of data and materials}

The datasets used and/or analyzed during the current study are available from the corresponding author on reasonable request.

\section{Authors' contributions}

HF, XZ and JW made substantial contributions to the conception and design of the study. HF, XZ, JW, YR, TT, TO, SH and $\mathrm{HM}$ contributed to the acquisition, analysis and interpretation of data. HF, JW and HM were involved in drafting the manuscript and revising it carefully for important intellectual content. All authors have participated sufficiently in the work to take public responsibility of appropriate portions of the content. All authors read and approved the final manuscript.

\section{Ethics approval and consent to participate}

All procedures performed involving human participants were in accordance with the approval by The Ethics Committee of Hyogo College of Medicine. Written informed consent was provided by all patients.

\section{Patient consent for publication}

Not applicable.

\section{Competing interests}

The authors declare that they have no competing interests.

\section{References}

1. Coussen LM and Werb Z: Inflammation and cancer. Nature 420: 860-867, 2002

2. Walczak H: TNF and ubiquitin at the crossroad of gene activation, cell death, inflammation, and cancer. Immunol Rev 244: 9-28, 2011.

3. Merga YJ, O'Hara A, Burkitt MD, Duckworth CA, Probert CS, Campbell BJ and Pritchard DM: Importance of the alternative NF- $\kappa \mathrm{B}$ activation pathway in inflammation-associated gastrointestinal carcinogenesis. Am J Physiol Gastrointest Liver Physiol 310: G1081-G1090, 2016.

4. Correa P: Helicobacter pylori and gastric carcinogenesis. Am J Surg Pathol 19 (Suppl 1): S37-S43, 1995.

5. Danesh J: Helicobacter pylori infection and gastric cancer: Systematic review of the epidemiological studies. Aliment Pharmacol Ther 13: 851-856, 1999. 
6. Tsujimoto H, Ono S, Ichikura T, Matsumoto Y, Yamamoto J and Hase K: Roles of inflammatory cytokines in the progression of gastric cancer: Friends or foes? Gastric Cancer 13: 212-221, 2010

7. Bockerstett KA and DiPaolo RJ: Regulation of gastric carcinogenesis by inflammatory cytokines. Cell Mol Gastroenterol Hepatol 4: 47-53, 2017.

8. Gao SP, Mark KG, Leslie K, Pao W, Motoi N, Gerald WL, Travis WD, Bornmann W, Veach D, Clarkson B and Bromberg JF: Mutations in the EGFR kinase domain mediate STAT3 activation via IL-6 production in human lung adenocarcinomas. J Clin Invest 117: 3846-3856, 2007.

9. Rebouissou S, Amessou M, Couchy G, Poussin K, Imbeaud S, Pilati C,Izard T, Balabaud C, Bioulac-Sage P and Zucman-Rossi J: Frequent in-frame somatic deletions activate gp130 in inflammatory hepatocellular tumours. Nature 457: 200-204, 2009.

10. Fukuda A, Wang SC, Morris JP IV, Folias AE, Liou A, Kim GE, Akira S, Boucher KM, Firpo MA, Mulvihill SJ and Hebrok M: Stat 3 and MMP7 contribute to pancreatic ductal adenocarcinoma initiation and progression. Cancer Cell 19: 441-455, 2011.

11. Johnson DE, O'Keefe RA and Grandis JR: Targeting the IL-6/JAK/STAT3 signalling axis in cancer. Nat Rev Clin Oncol 15: 234-248, 2018.

12. Yu H, Pardoll D and Jove R: STATs in cancer inflammation and immunity: A leading role for STAT3. Nat Rev Cancer 9: 798-809, 2009.

13. Judd LM, Alderman BM, Howlett M, Shulkes A, Dow C, Moverley J, Grail D, Jenkins BJ, Ernst M and Giraud AS: Gastric cancer development in mice lacking the SHP2 binding site on the IL-6 family co-receptor gp130. Gastroenterology 126: 196-207, 2004.

14. Judd LM, Bredin K, Kalantzis A, Jenkins BJ, Ernst M and Giraud AS: STAT3 activation regulates growth, inflammation, and vascularization in a mouse model of gastric tumorigenesis. Gastroenterology 131: 1073-1085, 2006.

15. Wu P, Wu D, Zhao L, Huang L, Shen G, Huang J and Chai Y: Prognostic role of STAT3 in solid tumors: A systematic review and meta-analysis. Oncotarget 7: 19863-19883, 2016.

16. Bowman T, Garcia R, Turkson J and Jove R: STATs in oncogenesis. Oncogene 19: 2474-2488, 2000.

17. Buettner R, Mora LB and Jove R: Activated STAT signaling in human tumors provides novel molecular targets for therapeutic intervention. Clin Cancer Res 8: 945-954, 2002.

18. Huang S: Regulation of metastases by signal transducer and activator of transcription 3 signaling pathway: Clinical implications. Clin Cancer Res 13: 1362-1366, 2007.

19. Kamran MZ, Patil P and Gude RP: Role of STAT3 in cancer metastasis and translational advances. Biomed Res Int 2013: 421821, 2013

20. Yu CC, Woods AL and Levison DA: The assessment of cellular proliferation by immunohistochemistry: A review of currently available methods and their applications. Histochem $\mathbf{J} 24$ : 121-131, 1992.

21. Leung WK and Sung JJ: Intestinal metaplasia and gastric carcinogenesis. Aliment Pharmacol Ther 16: 1209-1216, 2002.

22. Ushijima $T$ and Sasako M: Focus on gastric cancer. Cancer Cell 5: 121-125, 2004

23. Mitsuyama K, Sata $M$ and Rose-John S: Interleukin-6 trans-signaling in inflammatory bowel disease. Cytokine Growth Factor Rev 17: 451-461, 2006.

24. Gao Y, Zhao H, Wang P, Wang J and Zou L: The roles of SOCS3 and STAT3 in bacterial infection and inflammatory diseases. Scand J Immunol 88: e12727, 2018.

25. O'Shea JJ, Gadina M and Schreiber RD: Cytokine signaling in 2002: New surprises in the Jak/Stat pathway. Cell 109 (Suppl): S121-S131, 2002

26. Kubo M, Hanada T and Yoshimura A: Suppressors of cytokine signaling and immunity. Nat Immunol 4: 1169-1176, 2003.

27. Weber A, Hengge UR, Bardenheuer W, Tischoff I, Sommerer F Markwarth A, Dietz A, Wittekind C and Tannapfel A: SOCS-3 is frequently methylated in head and neck squamous cell carcinoma and its precursor lesions and causes growth inhibition. Oncogene 24: 6699-6708, 2005.

28. Huang L, Hu B, Ni J, Wu J, Jiang W, Chen C, Yang L, Zeng Y, Wan R, Hu G, et al: Transcriptional repression of SOCS3 mediated by IL-6/STAT3 signaling via DNMT1 promotes pancreatic cancer growth and metastasis. J Exp Clin Cancer Res 35: 27, 2016.

29. Jiang BG, Wang N, Huang J, Yang Y, Sun LL, Pan ZY and Zhou WP: Tumor SOCS3 methylation status predicts the treatment response to TACE and prognosis in HCC patients. Oncotarget 8: 28621-28627, 2017.
30. Galm O, Yoshikawa H, Esteller M, Osieka R and Herman JG: SOCS-1, a negative regulator of cytokine signaling, is frequently silenced by methylation in multiple myeloma. Blood 101: 2784-2788, 2003

31. Lindemann C, Hackmann O, Delic S, Schmidt N, Reifenberger G and Riemenschneider MJ: SOCS3 promoter methylation is mutually exclusive to EGFR amplification in gliomas and promotes glioma cell invasion through STAT3 and FAK activation. Acta Neuropathol 122: 241-251, 2011.

32. Kimura $\mathrm{K}$ and Takemoto $\mathrm{T}$ : An endoscopic recognition of the atrophic border and its significance in chronic gastritis Endoscopy 1: 87-97, 1969.

33. Kitahara F, Kobayashi K, Sato T, Kojima Y, Araki T and Fujino MA: Accuracy of screening for gastric cancer using serum pepsinogen concentration. Gut 44: 693-697, 1999.

34. Karibe T, Fukui H, Sekikawa A, Shiratori K and Fujimori T: EXTL3 promoter methylation down-regulates EXTL3 and heparan sulphate expression in mucinous colorectal cancers. J Pathol 216: 32-42, 2008

35. Herman JG, Graff JR, Myohanen S, Nelkin BD and Baylin SB Methylation-specific PCR: A novel PCR assay for methylation status of CpG islands. Proc Natl Acad Sci USA 93: 9821-9826, 1996.

36. He B, You L, Uematsu K, Zang K, Xu Z, Lee AY, Costello JF, McCormick F and Jablons DM: SOCS-3 is frequently silenced by hypermethylation and suppresses cell growth in human lung cancer. Proc Natl Acad Sci USA 100: 14133-14138, 2003.

37. Sekikawa A, Fukui H, Fujii S, Ichikawa K, Tomita S, Imura J, Chiba $\mathrm{T}$ and Fujimori T: REG Ialpha protein mediates an anti-apoptotic effect of STAT3 signaling in gastric cancer cells. Carcinogenesis 29: 76-83, 2008.

38. Fukui H, Sekikawa A, Tanaka H, Fujimori Y, Katake Y, Fujii S, Ichikawa K, Tomita S, Imura J, Chiba T and Fujimori T: DMBT1 is a novel gene induced by IL-22 in ulcerative colitis. Inflamm Bowel Dis 17: 1177-1188, 2011.

39. Ogata H, Kobayashi T, Chinen T, Takaki H, Sanada T, Minoda Y, Koga K, Takaesu G, Maehara Y, Iida M and Yoshimura A: Deletion of the SOCS3 gene in liver parenchymal cells promotes hepatitis-induced hepatocarcinogenesis. Gastroenterology 131: 179-193, 2006

40. Tischoff I, Hengge UR, Vieth M, Ell C, Stolte M, Weber A, Schmidt WE and Tannapfel A: Methylation of SOCS-3 and SOCS-1 in the carcinogenesis of Barrett's adenocarcinoma. Gut 56: 1047-1053, 2007.

41. Li Y, de Haar C, Chen M, Deuring J, Gerrits MM, Smits R, Xia B, Kuipers EJ and van der Woude CJ: Disease-related expression of the IL6/STAT3/SOCS3 signalling pathway in ulcerative colitis and ulcerative colitis-related carcinogenesis. Gut 59: 227-235, 2010.

42. Issa JP: CpG-island methylation in aging and cancer. Curr Top Microbiol Immunol 249: 101-118, 2000.

43. Ahuja N, Li Q, Mohan AL, Baylin SB and Issa JP: Aging and DNA methylation in colorectal mucosa and cancer. Cancer Res 58: 5489-5494, 1998.

44. Ishimoto $\mathrm{H}$ : Epigenetic alterations in cholangiocarcinoma-sustained IL-6/STAT3 signaling in cholangio-carcinoma due to SOCS3 epigenetic silencing. Digestion 79 (Suppl 1): S2-S8, 2009.

45. Bromberg J: Stat proteins and oncogenesis. J Clin Invest 109: $1139-1142,2002$.

46. Rahaman SO, Harbor PC, Chernova O, Barnett GH, Vogelbaum MA and Haque SJ: Inhibition of constitutively activate Stat 3 suppresses proliferation and induces apoptosis in glioblastoma multiforme cells. Oncogene 21: 8404-8413, 2002.

47. Wu WY, Li J, Wu ZS, Zhang CL, Meng XL and Lobie PE Prognostic significance of phosphorylated signal transducer and activator of transcription 3 and suppressor of cytokine signaling 3 expression in hepatocellular carcinoma. Exp Ther Med 2: 647-653, 2011.

48. Chiba R, Akiya M, Hashimura M, Oguri Y, Inukai M, Hara A and Saegusa M: ALK signaling cascade confers multiple advantages to glioblastoma cells through neovascularization and cell proliferation. PLoS One 12: e0183516, 2017.

49. Yoshida T, Kato J, Inoue I, Yoshimura N, Deguchi $\mathrm{H}$, Mukoubayashi C, Oka M, Watanabe M,Enomoto S, Niwa T, et al: Cancer development based on chronic active gastritis and resulting gastric atrophy as assessed by serum levels of pepsinogen and Helicobacter pylori antibody titer. Int J Cancer 134: $1445-1457,2014$ 
50. Adachi K, Mishiro T, Tanaka S and Kinoshita Y: Analysis of negative result in serum anti-H. pylori IgG antibody test in cases with gastric mucosal atrophy. J Clin Biochem Nutr 59: 145-148, 2016.

51. Enomoto S, Maekita T, Ohata H, Yanaoka K, Oka M and Ichinose M: Novel risk markers for gastric cancer screening: Present status and future prospects. World J Gastrointest Endosc 2: 381-387. 2010.

52. Watari J, Chen N, Amenta PS, Fukui H, Oshima T, Tomita T, Miwa H, Lim KJ and Das KM: Helicobacter pylori associated chronic gastritis, clinical syndromes, precancerous lesions, and pathogenesis of gastric cancer development. World J Gastroenterol 20: 5461-5473, 2014
53. Kato M, Nishida T, Yamamoto K, Hayashi S, Kitamura S, Yabuta T, Yoshio T, Nakamura T, Komori M, Kawai N, et al: Scheduled endoscopic surveillance controls secondary cancer after curative endoscopic resection for early gastric cancer: A multicentre retrospective cohort study by Osaka University ESD study group. Gut 62: 1425-1432, 2013.

This work is licensed under a Creative Commons Attribution-NonCommercial-NoDerivatives 4.0 International (CC BY-NC-ND 4.0) License. 